\title{
Extension of the multi-frequency ECRH system at ASDEX upgrade
}

\author{
D. Wagner ${ }^{1}$, J. Stober ${ }^{1}$, M. Kircher ${ }^{1}$, F. Leuterer ${ }^{1}$, F. Monaco ${ }^{1}$, M. Münich ${ }^{1}$, M. Schubert ${ }^{1}$, \\ H. Zohm ${ }^{1}$, G. Gantenbein ${ }^{2}$, J. Jelonnek ${ }^{2}$, M. Thumm ${ }^{2}$, A. Meier ${ }^{3}$, T. Scherer ${ }^{3}$, D. Strauss ${ }^{3}$, \\ W. Kasparek ${ }^{4}$, C. Lechte, ${ }^{4}$ B.Plaum ${ }^{4}$, A.Zach ${ }^{4}$, A.G. Litvak ${ }^{5}$, G.G. Denisov ${ }^{5}$, A. Chirkov ${ }^{5}$, \\ V. Malygin ${ }^{5}$, L.G. Popov ${ }^{6}$, V.O. Nichiporenko ${ }^{6}$, V.E. Myasnikov ${ }^{6}$, E.M. Tai ${ }^{6}$, \\ E.A. Solyanova ${ }^{6}$, S.A. Malygin ${ }^{6}$, and ASDEX Upgrade team \\ ${ }^{1}$ Max-Planck-Institut für Plasmaphysik, Boltzmannstr.2, D-85748 Garching, Germany, dietmar.wagner@ipp.mpg.de \\ ${ }^{2}$ Institut für Hochleistungsimpuls- und Mikrowellentechnik, \\ ${ }^{3}$ Institut für Angewandte Materialien-AWP, \\ Karlsruhe Institute of Technology, Kaiserstr. 12, D-76131 Karlsruhe, Germany \\ ${ }^{4}$ Institut für Grenzflächenverfahrenstechnik und Plasmatechnologie, Universität Stuttgart, \\ Pfaffenwaldring 31, D-70569 Stuttgart, Germany \\ ${ }^{5}$ Institute of Applied Physics, RAS, 46 Ulyanov St., Nizhny Novgorod, 603950, Russia \\ ${ }^{6}$ GYCOM Ltd, 46 Ulyanov St., Nizhny Novgorod, 603155, Russia
}

\section{Introduction}

Four two-frequency gyrotrons were in operation during the latest experimental campaign at ASDEX Upgrade (AUG), operating at 105 and $140 \mathrm{GHz}$ with a pulse length of $10 \mathrm{~s}$, corresponding to the maximum flat top time of AUG plasma discharges, and output powers close to $1 \mathrm{MW}$. The gyrotrons have single-stage depressed collectors and their efficiencies are around or above 50\%. Recently, an old $140 \mathrm{GHz}$ single-frequency ECRH system which was built in 1996 (4 gyrotrons with $500 \mathrm{~kW}$ output power and $2 \mathrm{~s}$ pulse length) has been dismantled. It is being replaced by four new $1 \mathrm{MW}$ two-frequency gyrotrons using the same launching positions with slightly modified launchers [1]. The new gyrotrons will be operated in cryogen-free superconducting magnets.

\section{Power Supplies}

For the new gyrotrons a semiconductor-based body modulator has been developed with a maximum output voltage of $32 \mathrm{kV}$, peak and average current of $1 \mathrm{~A}$ and $250 \mathrm{~mA}$, respectively. The voltage rise time is variable between $100 \mu \mathrm{s}$ and $1 \mathrm{~ms}$ and the switch-off time is below $10 \mu \mathrm{s}$. The cathode voltage is provided by a tetrodebased series tube modulator with improved control system and an insulating transformer and screen grid at high potential. The output voltage can be varied during the gyrotron pulse.

\section{Transmission Line}

The ECRH transmission lines at AUG are based on corrugated non-evacuated HE11 waveguides with $87 \mathrm{~mm}$ inner diameter (Fig. 1). The new gyrotrons are placed at a linear distance of $65 \mathrm{~m}$ away from the tokamak, which eliminates the influence of the tokamak stray magnetic field (from which we suffered in the old ECRH installation). The total length of the transmission lines is about $90 \mathrm{~m}$ and the maximum number of required miter bends is between 6 and 8. The Matching Optics Units (MOUs) are equipped with a pair of phase correcting mirrors for each frequency followed by two broadband polarizer mirrors (Fig. 2).

New water loads have been developed for 1 and $10 \mathrm{~s}$ pulse length and $1 \mathrm{MW}$ power (Fig. 3). Each MOU con- tains a $1 \mathrm{~s}$ water load which is used for system startup or intermediate conditioning. Each gyrotron can be connected to a single long-pulse load (1 MW, $10 \mathrm{~s}$ ). Shortpulse calorimetric loads (200 ms, $1 \mathrm{MW}$ ) can be installed in the MOUs and are permanently mounted at the AUG ports. Online power monitoring is provided by built-in directional couplers in the second phase-correcting mirrors of the MOUs and by an improved 2-frequency miter bend integrated power monitor at the end of each transmission line.

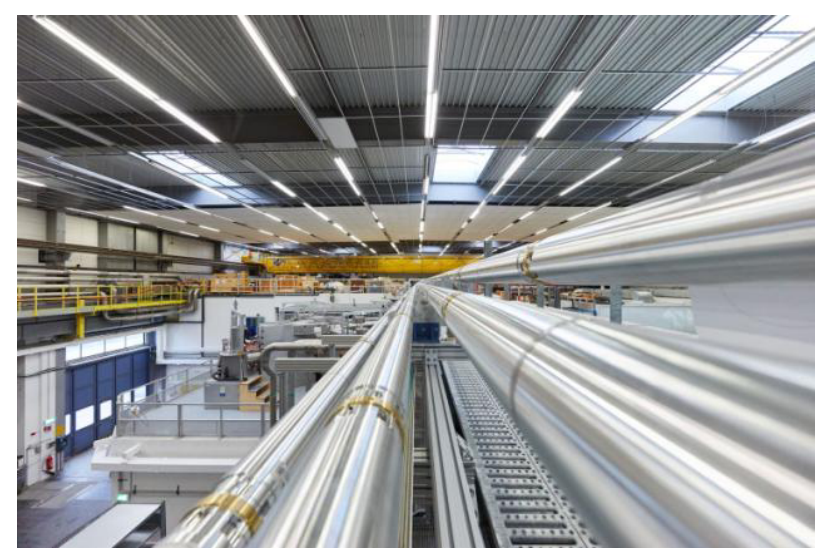

Fig. 1. View of the HE11 waveguide transmission line at ASDEX Upgrade

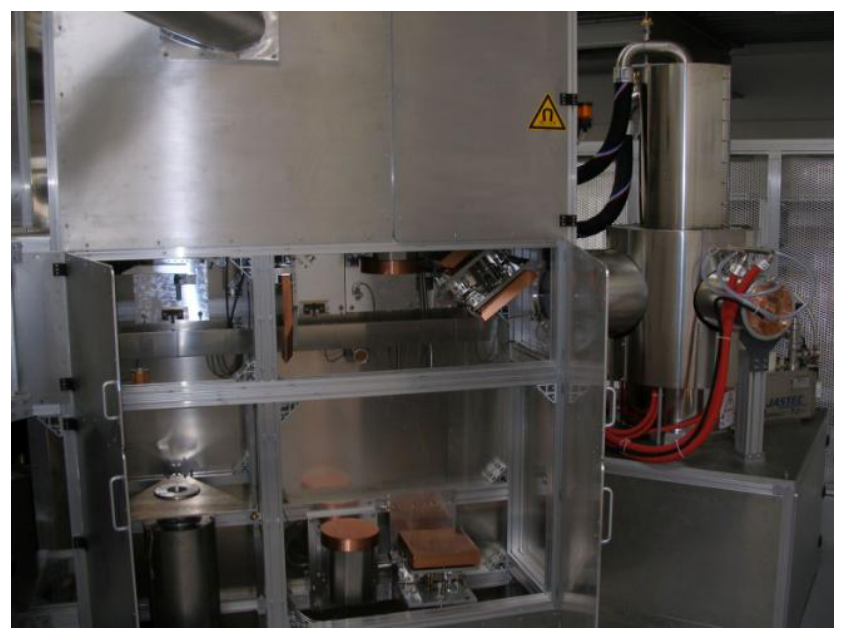

Fig. 2. Gyrotron (right)

connected to a Matching Optics Unit (left) 


\section{In-Vessel Reflectors for O2-Mode Heating}

The ASDEX Upgrade Tokamak has been equipped with a solid tungsten divertor, which allows to gain experience in operation under ITER-like heat loads. Progress has been made in controlling high power $\left(\mathrm{P}_{\text {heat }} \approx 20 \mathrm{MW}\right)$ discharges, where the power normalized to the major radius $\left(\mathrm{R}_{0}=1.65 \mathrm{~m}\right)$ is approaching ITER relevant values [2]. The potential threat resulting from the accumulation of tungsten in the plasma center can be effectively avoided, if the central heating power density is high enough. In principal, the electron cyclotron resonance heating (ECRH) system at ASDEX Upgrade (AUG) is able to fulfil this task, but it has to be operated in the $\mathrm{O} 2$ mode, since the plasma density in these experiments usually exceeds the X2 cut-off at the operating frequency $\mathrm{f}=140$ $\mathrm{GHz}$. In the AUG case, $\mathrm{O} 2$ mode single pass absorption is incomplete [3]. A second pass of the unabsorbed fraction, however, improves the situation significantly [4]. Therefore it was necessary to install special reflectors into the heat shield on the central column inside the AUG vacuum vessel. It is possible to generate an efficient oblique reflection for a given wavelength and beam geometry, if an optimized grating [5] is machined into the mirror surface. In addition, for each beamline a suitable beam dump has to be selected on the low field side. This is necessary in order to spread out the unabsorbed part of the beam after the second pass, which may typically contain $10 \%$ of the initial beam power.

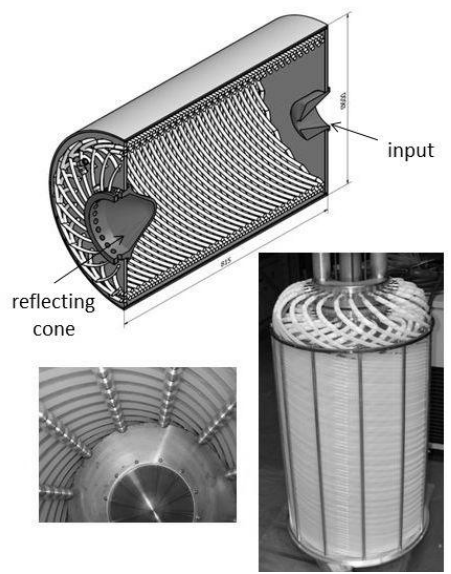

Fig. 3. High power water load for $1 \mathrm{MW}, 10 \mathrm{~s}$ with Teflon tubing

\section{Machine Protection}

In case of low ECRH absorption ASDEX Upgrade is protected by a number of stray radiation detectors (sniffer probes) [1]. Typical cases for low absorption are errors in the polarization of the injected beam, plasma cutoffs or operation regimes with low mm-wave absorption [3]. As an additional passive protection, an overlapping design of the tile edges (Fig. 4) on the inner heat shield of ASDEX Upgrade increases the shielding against mm-waves and reduces the risk of severe damage. The shielding factor has been measured on a laboratory test mock-up and its worst case value of $-14.4 \mathrm{~dB}(140 \mathrm{GHz})$ is considered as sufficient for protection of vital parts.

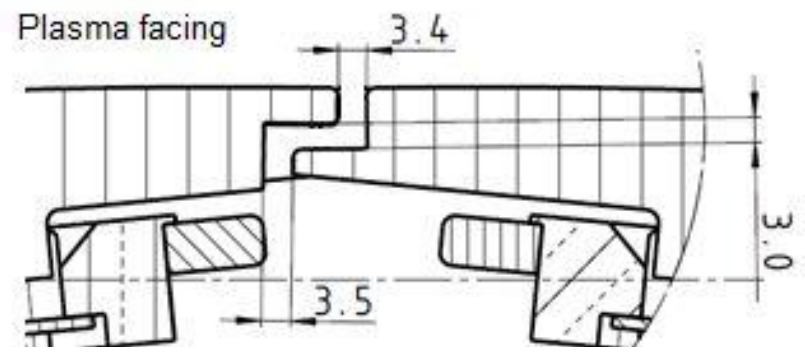

Fig. 4. Edges of heat shield tiles have been redesigned with a labyrinth-like "dog leg" structure in order to increase the shielding against millimeter waves

\section{References}

1. Wagner, D., et al. Status, Operation and Extension of the ECRH System at ASDEX Upgrade // Int. J. of Infrared, Millimeter and Terahertz Waves 2016. V. 37, P. 45-54.

2. Kallenbach, A., et al. Partial detachment of high power discharges in ASDEX Upgrade // Nuclear Fusion. 2015. V. 55. P. 053026.

3. Erckmann, $V$. and U. Gasparino, Electron cyclotron resonance heating and current drive in toroidal fusion plasmas // Plasma Phys. Control. Fusion 1994. V. 36, P. 1869.

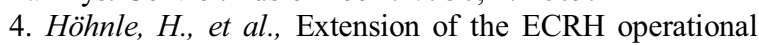
space with $\mathrm{O} 2$ and $\mathrm{X} 3$ heating schemes to control tungsten accumulation in ASDEX Upgrade// Nuclear Fusion. 2011. V. 51. P. 083013.

5. Mangold, O., et al., Optimization of microwave reflection gratings for electron cyclotron resonance heating in $\mathrm{O} 2$ mode // Conf. Digest of the 2004 Joint 29th Int. Conf. on Infrared and Millimeter Waves and 12th Int. Conf. on Terahertz Electronics. 2004. P. 717-718. (doi:10.1109/ ICIMW.2004.1422293). 